\title{
Signal Transduction Alteration
}

National Cancer Institute

\section{Source}

National Cancer Institute. Signal Transduction Alteration. NCI Thesaurus. Code C41534.

Signal Transduction Alteration involves a change in the quality of existing cellular processes by which a cell propag ates information from an extracellular signal through a series of biochemical reactions inside the cell to produce biological responses to events in the environment or internal milieu. 